\title{
Recovered Polypropylene Composites with High Impact Strength
}

\author{
PAUL GHIOCA ${ }^{1 *}$, LORENA IANCU1, RAMONA MARINA GRIGORESCU ${ }^{1}$, BOGDAN SPURCACIU1, MARIA RAPA², CORNEL CINCU 3 , \\ ALEXANDRA PICA ${ }^{3}$, ECATERINA MATEI ${ }^{4}$ \\ ${ }^{1}$ The National Institute of Research and Development for Chemistry and Petrochemistry ICECHIM, 202 Splaiul Independenei, \\ 060021, Bucharest, Romania \\ ${ }^{2}$ S.C. ICPAO S.A., 8 Carpati Street, 551022 Medias, Romania \\ ${ }^{3}$ The Research Institute of Advanced Coatings, 49A Theodor Pallady Blvd., 032258, Bucharest, Romania \\ ${ }^{4}$ Politehnica University of Bucharest, Center of Research and Eco-Metallurgical Expertise, 313 Splaiul Independenei, 060042, \\ Bucharest, Romania

\begin{abstract}
This paper presents a modification study of recovered polypropylene by melt alloying with a styrene-isoprene block-copolymer blend, thus ensuring the optimum conditions to obtain polypropylene composites with performance impact strength.
\end{abstract}

Keywords: recovered polypropylene, styrene-isoprene block-copolymers, melt alloying

The recovered polypropylene (RPP) is reintroduced into the economic circuit in a significant proportion by its reutilization as such or by blending it with native polypropylene in order to obtain technical parts and containers with uses excluding the food industry [1-5]. In this case, economical advantages are achieved due to the reduced cost of RPP, but the obtained products show no performant physical-mechanical properties, especially impact strength that is deficient even for the virgin polyolefin.

The RPP reintroducing in the economic circuit as composites though its modification with synthetic elastomers and various mineral or organic fillers is a very efficient method in economic terms but also regarding the performance physical-mechanical properties, especially the impact strength of composites higher then for virgin polypropylene [6-11].

Numerous studies regarding the polypropylene impact strength improvement by melt compounding with elastomers have established that the maximum efficiency is achieved when the melt viscosity of components, incompatible or with reduced compatibility, is as close, ideal equal [12-16].

The diene-styrene block-copolymers and their hydrogenated derivatives are the most used elastomers for polypropylene melt compounding due to their thermoplastic properties and to the fact that they do not require vulcanization $[17,18]$.

The melt viscosity of recovered polypropylene varies depending on the provenience of collected objects and their degradation degree, thus complying the optimum alloying condition needs a very wide assortment of dienestyrene block-copolymers to ensure the whole range of melt viscosities of various batches of RPP, that is obvious impossible.

Taking into account these considerations, the paper presents a study of RPP melt alloying with a styreneisoprene block-copolymers blend, designed to have a melt viscosity very close to that of the polyolefin.

\section{Experimental part}

The linear styrene-isoprene block-copolymers were synthetized by sequential anionic polymerization of monomers in cyclohexane solution using n-butyl lithium as initiator, according to the methods described in literature
[19-21]. After synthesis, the linear styrene-isoprene-styrene block-copolymers (SIS) were stabilized directly in the cyclohexane solution with 2,6-ditert-butyl-4-methyl phenol ( $1 \%$ of the elastomer content). The block-copolymers were separated from the cyclohexane solution by desolvation with hot water and water vapors, dried in air and finally under vacuum at $60^{\circ} \mathrm{C}$ in an oven.

The molecular masses of final block-copolymer and of their component blocks, and of the samples collected during synthesis were determined by gel permeation chromatography (GPC). The polystyrene content was confirmed by IR spectroscopy. The physical-mechanical properties were determined on polymeric films with a thickness of about $1 \mathrm{~mm}$ obtained by a centrifugal casting from the toluene solution of styrene-isoprene blockcopolymers.

Two styrene-isoprene block-copolymers were synthesized. Their properties are presented in table 1.

To achieve composites with high impact strength, a RPP recovered especially from transport shuttles and industrial containers was used, its properties being presented in table 2.

RPP modification by melt alloying with styrene-isoprene block-copolymers was achieved on a laboratory roller at $185-190{ }^{\circ} \mathrm{C}$ with a friction coefficient of 1.18-1.2. The dosage of the styrene-isoprene block-copolymers and the mixture thereof varied in the range $5-30 \%$. The blockcopolymers blend was obtained on the roller at $160^{\circ} \mathrm{C}$ and after homogenization a foil with $2-3 \mathrm{~mm}$ thickness was obtained and then granulated.

The following working method was used for all the compounds:

-Polyolefin attachment on the roller: 5 - 6 min

-Styrene-isoprene block-copolymer incorporation: 3- 4 $\min$

-Blend homogenization: 3 - 5 min.

The compounds were removed from the roller as foils with about $2 \mathrm{~mm}$ thickness from which were obtained plates by pressing them at a temperature of $185-190^{\circ} \mathrm{C}$ for $15 \mathrm{~min}$ with a pressure of $200 \mathrm{~N} / \mathrm{m}^{2}$.

There were obtained in these conditions plates with 1 $\mathrm{mm}$ thickness aimed for determining the physicalmechanical properties in dynamic regime and for thermal behavior (DSC) as well as plates with $4 \mathrm{~mm}$ thickness for 


\begin{tabular}{|c|l|c|c|}
\hline No. & Property & SIS l & SIS 2 \\
\hline 1. & Polystyrene content, \% & 20.2 & 29.8 \\
\hline 2. & Total mass, g/mole & 133800 & 76400 \\
\hline 3. & Polystyrene block mass, g/mole & 13500 & 11400 \\
\hline 4. & Polyisoprene block mass, g/mole & 106800 & 53600 \\
\hline 5. & Tensile strength, MPa & 8.7 & 11.4 \\
\hline 6. & Elongation at break, \% & 1580 & 1320 \\
\hline 7. & Hardness, ${ }^{\circ}$ Sh D & 34 & 42 \\
\hline 8. & Melt flow index at $190^{\circ} \mathrm{C}$ with a load of $5 \mathrm{~kg}, \mathrm{~g} / 10 \mathrm{~min}$ & 4.4 & 20.6 \\
\hline
\end{tabular}

Table 1

STYRENE-ISOPRENE

BLOCK-COPOLYMER PROPERTIES

\begin{tabular}{|c|l|c|}
\hline No & Property & RPP \\
\hline 1. & Crystallinity, \% & 74.5 \\
\hline 2. & Hardness, ${ }^{\text {Sh D }}$ & 72 \\
\hline 3. & Tensile strength, $\mathrm{MPa}$ & 36.4 \\
\hline 4. & Elongation at break, $\%$ & 40 \\
\hline 5. & Izod impact strength at $+20^{\circ} \mathrm{C}, \mathrm{Kg} / \mathrm{m}^{2}$ & 4.8 \\
\hline 6. & Izod impact strength at $-20^{\circ} \mathrm{C}, \mathrm{Kg} / \mathrm{m}^{2}$ & 3.2 \\
\hline 7. & Melt flow index at $190{ }^{\circ} \mathrm{C}$ with a load of $5 \mathrm{~kg}, \mathrm{~g} / 10 \mathrm{~min}$ & 8.1 \\
\hline
\end{tabular}

Table 2

THE PHYSICO-MECHANICAL PROPERTIES OF RECOVERED POLYPROPYLENE naraness tests and trom wnicn notcnea specimens were stamped for Izod impact strength determination.

Tensile properties were assessed using a FPZ 100 dynamometer, with an elongation rate of $50 \mathrm{~mm} / \mathrm{min}$, on 5A type specimens stamped according to SR EN ISO 52796 from the $1 \mathrm{~mm}$ thick plates.

Shore D hardness was measured on $4 \mathrm{~mm}$ thickness pressed plates samples.

Izod impact strength was determined on notched specimens stamped from the $4 \mathrm{~mm}$ plates, at +20 and $20^{\circ} \mathrm{C}$, according to SR EN ISO 180-2009, using a Ceast instrument.

The melt flow index was determined on a laboratory plastometer, according to SR EN ISO 1133-93, at $190^{\circ} \mathrm{C}$, under $5 \mathrm{~kg}$ loading.

\section{Results and discussions}

The studies performed in the last decades to improve the deficient impact strength of polyolefins show a high degree of crystallinityaimed the modification both of their crystalline and amorphous phase. It was established that although it is minority, amorphous phase change plays the main role in increasing the impact strength. Using the melt alloying with elastomers leads to the largest increasing of polypropylene impact strength [12-14].

The styrene-diene block-copolymers have proven to be the most suitable in polypropylene modification because they are thermoplastic materials and have a very good processability at temperatures higher than the glass transition temperature of polystyrene blocks (above 100 ${ }^{\circ} \mathrm{C}$ ), do not require vulcanization and show vulcanized rubber properties at the normal use temperature of polyolefin composites (below $100^{\circ} \mathrm{C}$ ).

The intensity level of improvement of polypropylene composites impact strength is controlled by the elastomer domains size and their dispersion degree into the polyolefin matrix, the maximum performance being obtained when the melt viscosities of components are closer. For this purpose, is was obtained a blend of the two styreneisoprene block-copolymers in a SIS 1 / SIS 2 proportion of $25: 75$ that presented a melt flow index of $8.2 \mathrm{~g} / 10 \mathrm{~min}$ close to the RPP one $(8.1 \mathrm{~g} / 10 \mathrm{~min})$.

The RPP composites modified with the suitable styreneisoprene block-copolymers blend and with individual elastomers were achieved on roller in the above mentioned conditions.

The presence of the styrene-isoprene block-copolymers in the polyolefin matrix lowers the crystallinity degree of composites, the decreasing being correlated almost linear with increasing the elastomers ratio in the system (fig. 1).

As can be seen in figure 1, the elastomers presence in the compound produces to a small extend the crystallinity disruption, the effect being more pronounced in case of the styrene-diene block-copolymers blend as a results of a stronger interpenetration of elastomer domains of the blend into the crystalline lattice, the influence being facilitated of their optimum dimensions.

The styrene-isoprene block-copolymer domains dispersed mainly into the RPP amorphous phase acts as

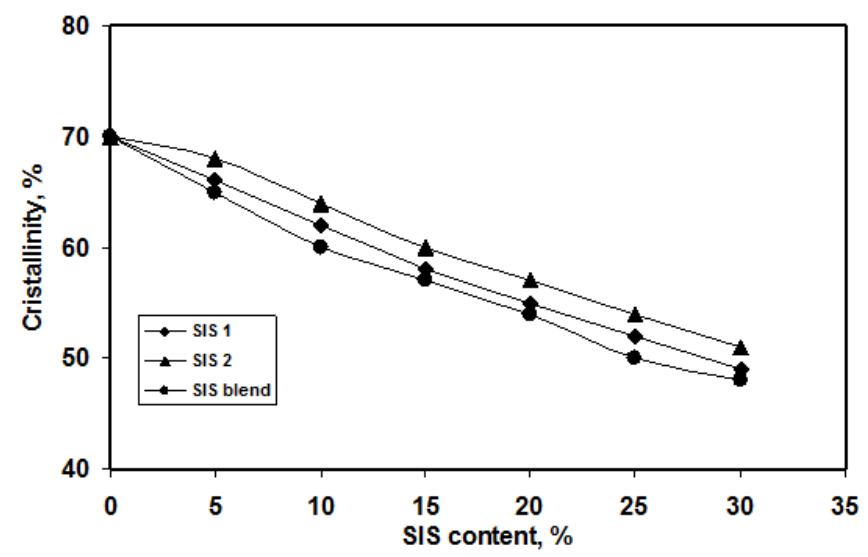

Fig. 1. The cristallinity variation of RPP-SIS blends depending on the SIS content 


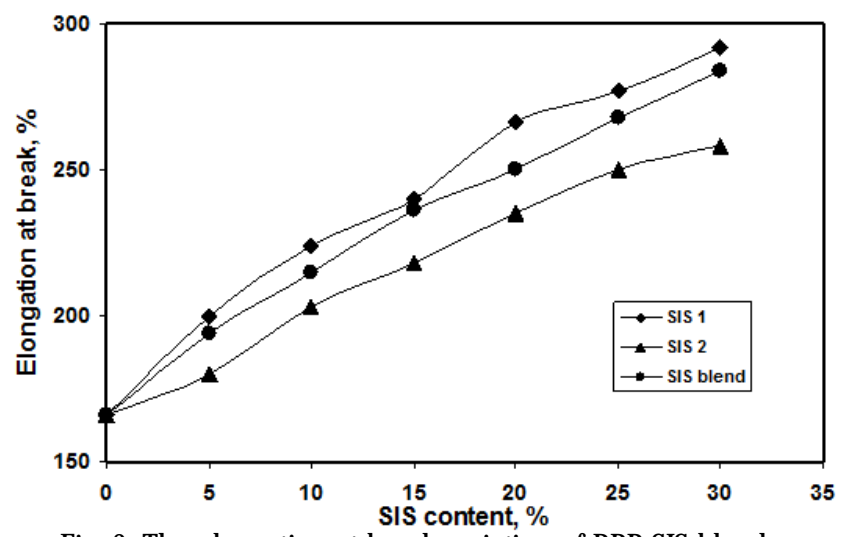

Fig. 2. The elongation at break variation of RPP-SIS blends depending on the SIS content

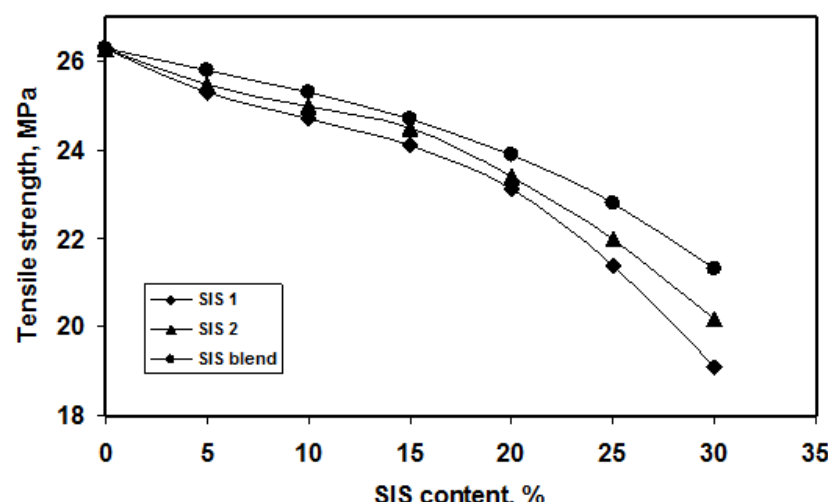

Fig. 3. The tensile strength variation of RPP-SIS blends depending on the SIS content

an extender and have an elasticizing role, the effect being demonstrated specifically by the increase of the elongation at break (fig. 2) to the detriment of the tensile strength that decreases (fig. 3).

The most favorable distribution of the elastomer phase formed by the styrene-isoprene block-copolymers blend makes that its elastic domains take more uniform the deformation stresses produced when the material is subjected to mechanical shocks. Moreover, this phase enables a more efficiently loads dispersion, thus explaining the greater values of the impact strength of the corresponding polypropylene composites both at positive and negative temperatures (figs. 4 and 5).

The maximum composites elasticization produced by the styrene-isoprene block-copolymers blend is highlighted also by the smaller values of the hardness as can be seen in figure 6.

Patrick diagrams that correlate the most important physical-mechanical properties (impact and tensile strength) of the polypropylene composites deciding their

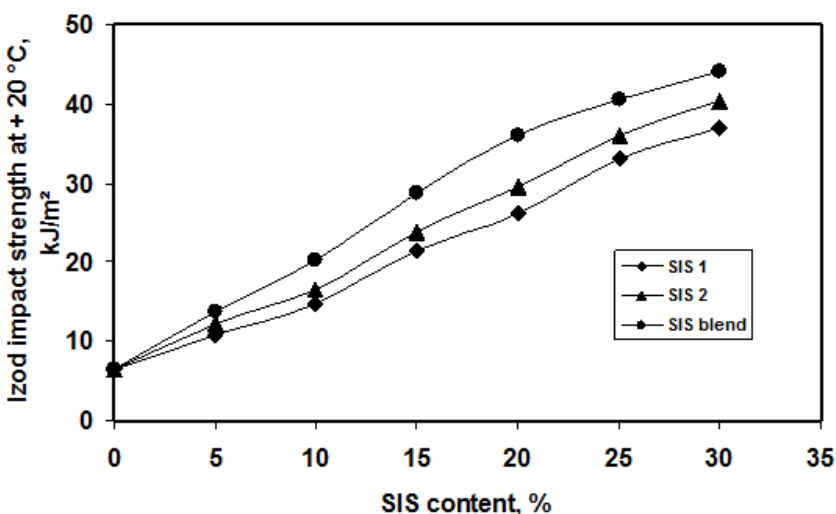

Fig. 4. The variation of the Izod impact strength at $+20^{\circ} \mathrm{C}$ of RPP-SIS blends depending on the SIS content

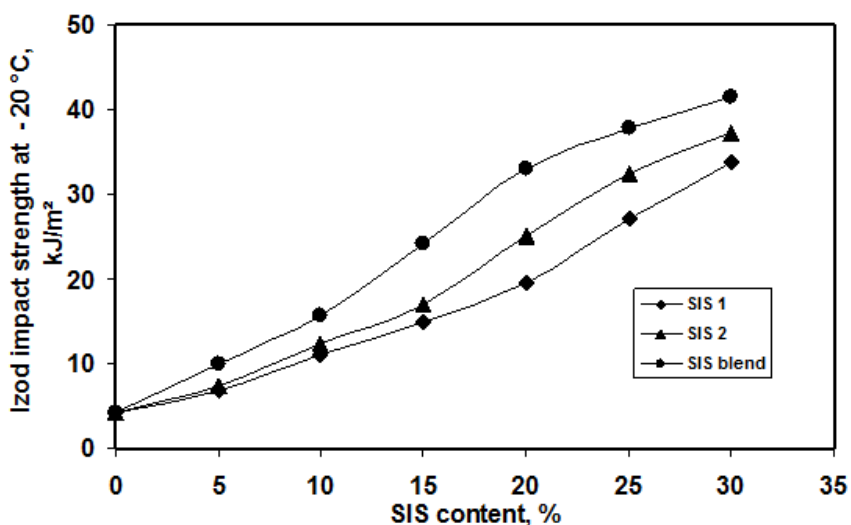

Fig. 5. The variation of the Izod impact strength at $-20{ }^{\circ} \mathrm{C}$ of RPP-SIS blends depending on the SIS content

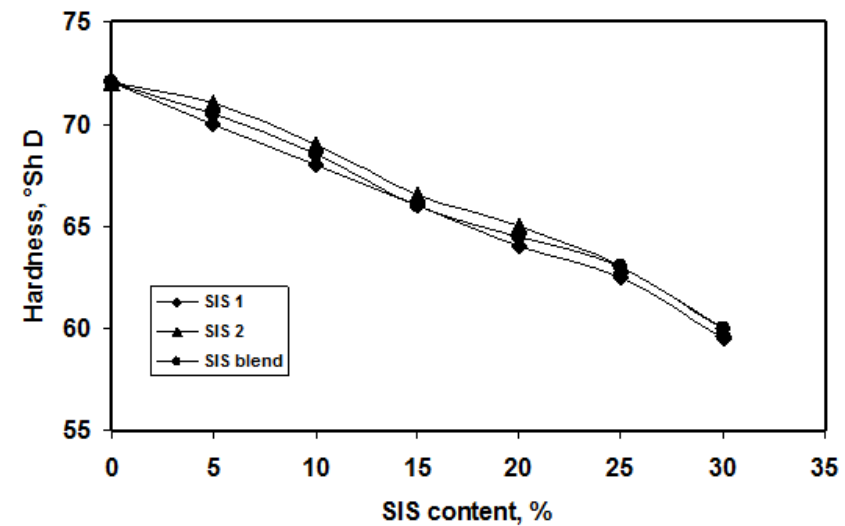

Fig. 6. The hardeness variation of RPP-SIS blends depending on the SIS content

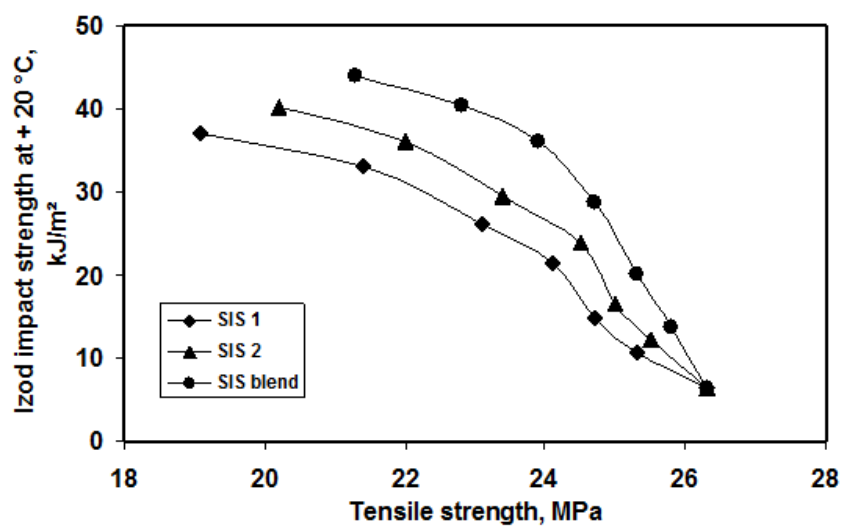

Fig. 7. The variation of the Izod impact strength at $+20^{\circ} \mathrm{C}$ of RPP-SIS blends depending on the tensile stregth

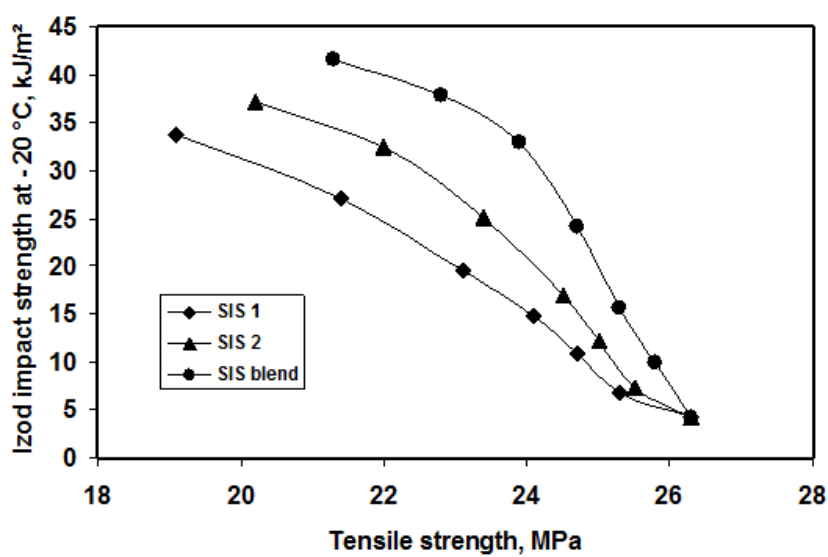

Fig. 8. The variation of the Izod impact strength at $-20{ }^{\circ} \mathrm{C}$ of RPP-SIS blends depending on the tensile stregth

use domain are presented in figures 7 and 8 , the styreneisoprene block-copolymers dosage being increased from right to left gradually with $5 \%$. These diagrams allow an 
easy selection of the styrene-isoprene block-copolymers proportion that ensures the optimum balance between these properties corresponding to the composites applications requirements.

The Patrick diagrams best outline, by the highest values of composites impact and tensile strength, the maximum modification effect of RPP by melt alloying produced by the styrene-isoprene block-copolymers blend with calculated composition which ensures a melt viscosity close to the RPP one.

\section{Conclusions}

The study confirmed that the optimal modification by melt alloying of RPP with styrene-isoprene blockcopolymers is achieved when the melt viscosity of the two components is close as possible.

Because the melt viscosity of recovered polypropylene varies depending on the nature and degradation degree of collected items, the viscosity of the elastomeric modifier was adjusted to be as close of the polypropylene sort by blending two styrene-isoprene block-copolymers with different melt flow indexes.

Thus RPP composites with high impact strength and maximum physical-mechanical properties were obtained, highlighting especially the impact strength values higher on average with $25 \%$ compared to the composites with individual styrene-isoprene block-copolymers.

Acknowledgements: This work was supported by a grant of the Romanian National Authority for Scientific Research, CNDI-UEFISCDI, project number 67/2012.

\section{References}

1.RAJ M.M., PATEL H. V., RAJ L. M., PATEL N. K., Int. Journal of Sci. Invention Today (IJSIT), Vol. 2 (3), 2013, p. 194;

2.DUARTE G. W., PELLEGRIN M. Z., JUNIOR J. F., SANTOS A.L.G., RIELLA H. G., FIORI M. A., J. Mat. Sci. Res., Vol 3 (1), 2014, p. 94;
3.AL-SALEM S. M., LETTIERI P., BAEYENS J., Waste Managemant, 29, 2009, p. 2625;

4.ACHILIAS D. S., MEGALOKONOMOS P., KARAYANNIDIS G. P., J. Envirom. Prot. Ecology 7, 2006, p. 407;

5.AURREKOTXEA J ., SARRIONANDIA M.A., URRUTIBEASCOA I., J. Mater. Sci., 36, 2011, p. 2607;

6.HERNANDEZ M., ICHAZO M. N, GONZALES I ., ALBANO C., SANTANA O., Acta Microscopica 17 (1), 2008, p. 66;

7.WEI L., MIAO Q., CHENG G - J., China Plastics Industry, 2006, p. 51; 8.MEIJIER H. E. H., GOYAERT L. E., Prog. Polym. Sci., 30, 2006, p. 915; 9.TORTORELLA N. , BEATTY C. L., Polymer Engineering $\&$ Science, 48 (11), 2008, p. 2098;

10.SHASHIDHARA G. M., KAMESHWARI-DEVI S. H., Indian J ournal of Engineering \& Materials Sciences, 18, 2011, p. 69;

11.MASSEY D. L., Film Properties of Plastics and Elastomers, Plastic Desing Library, 2004, p. 177;

12.KARGER-KOCSIS J., Polypropylene: Structure, Blends and Composites, Chapman \& Hall, 1995;

13.KARGER - KOCSIS, J., Popypropylene: An A-Z Reference, Kluwer Publishers, Dordrecht, 1999, p. 127;

14.UTRACKI, L. A., WILKIE C. A., Polymer Blends Handbook, Spriger 2014;

15.GHIOCA P., IANCU L., SPURCACIU B., COSEREA R. M., CINCU C., GARDU R., Mat. Plast. 50, no.1, 2013, p. 32

16.GHIOCA P., SPURCACIU B., IANCU L., GRIGORESCU R., RAPA M., GROSU E., MATEI E., BERBECARU C., PICA A., GARDU R., CINCU C., Mat. Plast. 52, no. 3, 2015, p. 281

17.HOLDEN G., LEGGE N. G., SCHRODER E., Thermoplastic Elastomers, Hauser Publishers, Viena, 2006;

18.IASO O., EGNIZABAL J. I., NAZABAL J ., Compozite Sci. Technol. 67 (13), 2007, p. 2854;

19.HOLDANG G., Thermoplastic Elastomers in Applied Plastics Engineering Handbook: Processing and Materials, Elsevier, Oxford UK, 2011, p. 77;

20.HSIEH, H. L., QUIRK, R., Anionic Polymerization, Marcel DAEKKER, New York, 2008;

21.GHIOCA P. si altii, Brevet RO 109850, 1995

Manuscript received: 4.10 .2016 